\title{
Evaluation of the Relationship Between Platelet Indices and Mitral Restenosis After Percutaneous Mitral Balloon Valvuloplasty
}

\author{
(1) Ömer Taşbulak1, (1) Ahmet Anıl Şahin2, (1) Mustafa Duran3, (1) Serkan Kahraman1, (1) Ömer Çelik1
}

1University of Health Sciences Turkey, Mehmet Akif Ersoy Thoracic and Cardiovascular Surgery Training and Research Hospital, İstanbul, Turkey ${ }^{2}$ Haliç University Faculty of Medicine, Department of Cardiology, İstanbul, Turkey

${ }^{3}$ Konya Training and Research Hospital, Clinic of Cardiology, Konya, Turkey

\begin{abstract}
Objectives: Percutaneous mitral balloon valvuloplasty (PMBV) has been established as an effective and safe treatment modality for symptomatic patients with severe rheumatic mitral stenosis. Wilkin scores $\leq 8$ are associated with higher rates of procedural success and lower rates of restenosis. It is well-known that platelets have a substantial role in thromboembolic complications of rheumatic mitral stenosis and various studies have showed that increases platelet (PLT) activity in rheumatic mitral stenosis. The aim of this study was to assess the usefulness of PLT indices as a predictor of restenosis in patients who underwent PMBV.

Materials and Methods: We retrospectively enrolled 178 consecutive patients who underwent PMBV. Patients were classified into two groups. The study group ( $\mathrm{n}=21$ ) included patients whom we performed redo PMBV during their followups as a result of mitral restenosis following previous PMBV (index procedure) and the control group ( $\mathrm{n}=157)$ included patients who did not undergo a redo PMBV. PLT indices including PLT count, Plateletcrit (PCT) and mean platelet volume (MPV) values were evaluated in these groups.

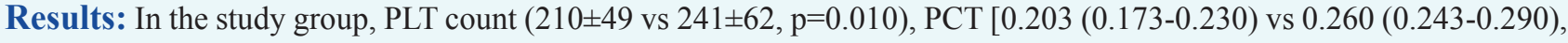
$\mathrm{p}<0.001]$ and MPV [9.7 (8.7-11.1) vs 10.5 (9.8-12.0), $\mathrm{p}=0.021]$ values were significantly higher in the restenosis group when compared to the control group. Receiver operating characteristic analysis showed cut-off values for MPV crossed
\end{abstract}

Address for Correspondence: Ahmet Anıl Şahin, Haliç University Faculty of Medicine, Department of Cardiology, İstanbul, Turkey e-mail: aanilsahin@hotmail.com ORCID: orcid.org/0000-0003-1956-2348

Received: 25.09.2020 Accepted: 13.11.2020

Cite this article as: Taşbulak Ö, Şahin AA, Duran M, Kahraman S, Çelik Ö. Evaluation of the Relationship Between Platelet Indices and Mitral Restenosis After Percutaneous Mitral Balloon Valvuloplasty. EJCM 2020;8(4):171-179.

DOI: 10.32596/ejcm.galenos.2020.09.048

${ }^{\circ}$ Copyright 2020 by Heart and Health Foundation of Turkey (TÜSAV) / E Journal of Cardiovascular Medicine published by Galenos Publishing House. 


\section{Abstract}

the curve at 9.65 (sensitivity $81.0 \%$ and specificity $49.7 \%$ ) and for PCT crossed the curve at 0.241 (sensitivity $76.2 \%$ and specificity $87.9 \%$ ).

Conclusion: PLT indices including PLT count, MPV and PCT might be feasible and easy parameters to predict possible restenosis after PMBV.

Keywords: Rheumatic mitral stenosis, platelet, platelecrit, percutaneous mitral balloon valvuloplasty

\section{Introduction}

Percutaneous mitral balloon valvuloplasty (PMBV) is an effective and safe treatment modality for symptomatic patients with severe rheumatic mitral stenosis in clinical practice $^{(1-3)}$. Studies in literature demonstrated that preprocedural clinical and echocardiographic characteristics and post-procedural outcomes had strong association in between ${ }^{(4)}$. In current clinical practice, Wilkins score (WS) is used to determine the morphology of mitral valve in transthoracic echocardiography (TTE) and score includes leaflet thickening, calcification, mobility and subvalvular fusion ${ }^{(5,6)}$. WS $\leq 8$ is associated with higher rate of procedural success and lower rate of restenosis ${ }^{(7)}$. Long-term adverse events after PMBV including mitral restenosis, occurrence of mitral regurgitation (MR), or progression of other valvular diseases were evaluated in previous studies. According to those studies, the incidence of restenosis was approximately $40 \%$ depending on the patient population, valve morphology, and duration of follow-up. In addition, major predictive factors with regard to being free from restenosis were WS $\leq 8$ and postprocedural mitral valve area (MVA) $\geq 2.0 \mathrm{~cm}^{2(8,9)}$.

Platelets have substantial role in thromboembolic complications of rheumatic mitral stenosis. Evidence by in vivo hemostatic markers revealed that rheumatic mitral stenosis was associated with increased platelet (PLT) activity ${ }^{(10,11)}$. Increased PLT activity caused increased production of thromboxane $\mathrm{A} 2$ and beta thromboglobulin, which resulted in a pro-thrombotic state in this patient population $^{(12)}$. PLT indices such as PLT count, mean platelet volume (MPV), and plateletcrit (PCT) are measured by automated blood cell analyzers and are reliable markers of PLT activity.

Therefore, in this study, we aimed to evaluate the usefulness of PLT indices as a predictor of restenosis and assessed long-term outcomes in patients who underwent PMBV.

\section{Materials and Methods}

\section{Study Population}

We retrospectively enrolled 178 consecutive patients presenting with symptomatic rheumatic mitral stenosis with favorable valve morphology, who underwent PMBV at our hospital between January 2010 and December 2019. Informed consent was obtained from all patients in accordance with a protocol approved by the local ethics committee (Mehmet Akif Ersoy Thoracic and Cardiovascular Surgery Training and Research Hospital Ethics Committee, decision no: 2020/58, date: 18.08.2020). Patients with MR more than mild or evidence of left atrial (LA) thrombus by transesophageal echocardiography (TEE) were excluded from the study because those parameters were contraindications for PMBV. Patients with concomitant valve disease requiring surgical intervention and patients indicated for coronary artery bypass surgery were also excluded.

Then, patients were classified into two groups based on their follow-up findings. The study group was defined as patients whom we performed redo PMBV during their follow-up as a result of mitral restenosis 
following previous PMBV (index procedure) and the control group was defined as patients who did not undergo a redo PMBV. In the study group, restenosis was defined as a decrease in MVA $>50 \%$ after the index PMBV together with MVA $\leq 1.5 \mathrm{~cm}^{2}$ during followup. For each group, demographic characteristics, past medical records, laboratory values, procedural information, TTE and TEE parameters were noted. Echocardiographic evaluation included left ventricular ejection fraction (LVEF), MVA, systolic pulmonary artery pressure (sPAP), mean diastolic mitral gradient, WS, and LA diameter.

\section{Laboratory Measurements}

Blood samples were drawn from the ante-cubital vein after a 12-hour fasting period and at most 24 hours before the procedure. PLT indices were measured in a blood sample collected in dipotassium EDTA tubes. An automatic blood counter (Sysmex, XT-2000i) was used for whole blood counts. PLT indices were measured within 30 minutes after sampling to prevent EDTA-induced PLT swelling. PCT, which defines the mass of PLT, is the volume occupied by PLT in the blood as a percentage. PCT was estimated according to the formula of PCT $=$ PLT count 'MPV/10.000 $0^{(13,14)}$.

\section{Echocardiographic Assessment}

All patients underwent TTE examination using a GE Vingmed Vivid 5 echocardiography device (GE Vingmed Ultrasound, Horten, Norway) before the procedure. MVA and other conventional echocardiographic measurements in our center are routinely performed according to American Echocardiography Society criteria in daily practice ${ }^{(15)}$. Mitral valve apparatus morphology was evaluated by using WS which included semi-quantitative assessment of leaflet mobility and thickening, subvalvular changes, and valve calcification according to previous definitions ${ }^{(6)}$. In addition, all patients routinely undergo TEE examination in our center within 24 hours before the planned procedure in order to rule out left atrial or appendage thrombosis and assessment of mitral annular diameter and morphology of atrial septum. Pre-procedural echocardiographic parameters were noted for every patient.

\section{Procedural Technique}

PMBV was performed via the trans venous (antegrade) approach through the femoral vein using a transseptal Brockenbrough needle as previously described ${ }^{(16)}$. Initial balloon size was selected according to body surface area. Maximum balloon size was determined by the following formula: [patient height $(\mathrm{cm}) / 10+10]^{(17)}$. All procedures were performed under TEE guidance. Procedure related mitral valve regurgitation was assessed by using echocardiography. According to our study, successful PMBV was defined as post-procedural MVA $\geq 1.5 \mathrm{~cm}^{2}$ by Gorlin formula and post-procedural MR less than moderate by echocardiographic or angiographic evaluation immediately after PMBV.

\section{Statistical Analysis}

Statistical analysis was made using the computer software Statistical Package for Social Sciences (IBM SPSS Statistics for Windows, IBM Corp., Armonk, New York, USA). Data were expressed as "n (\%)" for categorical variables. The Pearson chi-square and Fisher exact tests were performed for categorical variables. After fitness to normal distribution was analyzed with the Kolmogorov-Smirnov test, data were expressed as "median $\left(25^{\text {th }}\right.$ and $75^{\text {th }}$ percentiles)" for variables without a normal distribution and mean \pm standard deviation for variables with normal distribution. While the Student- $t$ test was used to compare quantitative variables with normal distribution, the Mann-Whitney $U$ test was used to compare quantitative variables without a normal distribution. Receiver operating characteristic (ROC) analysis was conducted to determine the optimal PCT and MPV value to indicate mortality in terms of both sensitivity and specificity. The long-term restenosis curve for both MPV and PCT was analyzed using the KaplanMeier method, and statistical assessment was performed using the log-rank test. A $p$ value $<0.05$ was considered to be statistically significant. 


\section{Results}

Baseline clinical and demographic characteristics of each group were provided in Table 1. There were no significant differences between two groups in terms of baseline clinical and demographic characteristics. On the other hand, the incidence of diabetes mellitus (DM) [7 $(4.5 \%)$ vs $4(19.0 \%), p=0.028]$ and the presence of atrial fibrillation (AF) [28 (17.8\%) vs $12(57.1 \%), \mathrm{p}<0.001]$ were significantly higher in the study group compared to the control group. One hundred and fifty-seven patients without restenosis had PMBV between 27 and 84 months ago and restenosis was not detected during their follow up. Twenty-one patients with restenosis had previous PMBV between 36 and 60 months ago and had their redo PMBV in our hospital during their follow-up.

Table 1. Baseline demographic and clinical variables of study population

\begin{tabular}{|c|c|c|c|}
\hline & $\begin{array}{l}\text { Restenosis }(-) \\
(n=157)\end{array}$ & $\begin{array}{l}\text { Restenosis (+) } \\
(n=21)\end{array}$ & $p$ value \\
\hline Age (years) & $42 \pm 11$ & $41 \pm 11$ & 0.536 \\
\hline Sex - female, n (\%) & $127(80.9)$ & $19(90.5)$ & 0.227 \\
\hline \multicolumn{4}{|c|}{ NYHA classification before PMBV } \\
\hline NYHA I & $10(6.4)$ & $2(1.4)$ & \multirow{4}{*}{0.335} \\
\hline NYHA II & $101(64.3)$ & $11(9.8)$ & \\
\hline NYHA III & $42(87.5)$ & $6(12.5)$ & \\
\hline NYHA IV & $4(2.5)$ & $2(9.5)$ & \\
\hline $\begin{array}{l}\text { Coronary artery } \\
\text { disease }(n, \%)\end{array}$ & $6(3.8)$ & $1(4.8)$ & 0.591 \\
\hline $\begin{array}{l}\text { Prior } \\
\text { cerebrovascular } \\
\text { event }(n, \%)\end{array}$ & $6(3.8)$ & $0(0)$ & 0.465 \\
\hline $\begin{array}{l}\text { Diabetes mellitus } \\
(\mathrm{n}, \%)\end{array}$ & $7(4.5)$ & $4(19.0)$ & 0.028 \\
\hline $\begin{array}{l}\text { Hypertension } \\
(n, \%)\end{array}$ & $16(10.2)$ & $5(23.8)$ & 0.080 \\
\hline $\begin{array}{l}\text { Peripheral embolic } \\
\text { event }(n, \%)\end{array}$ & $1(0.6)$ & $1(4.8)$ & 0.223 \\
\hline $\begin{array}{l}\text { Presence of atrial } \\
\text { fibrillation }(n, \%)\end{array}$ & $28(17.8)$ & $12(57.1)$ & $<0.001$ \\
\hline $\begin{array}{l}\text { Follow-up period } \\
\text { (months) }\end{array}$ & $60(27-84)$ & $48(36-60)$ & 0.377 \\
\hline
\end{tabular}

In the study group, PLT $(210 \pm 49$ vs $241 \pm 62, \mathrm{p}=0.010)$,

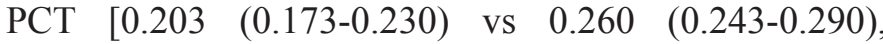
$\mathrm{p}<0.001]$ and MPV [9.7 (8.7-11.1) vs 10.5 (9.8-12.0), $\mathrm{p}=0.021]$ values were significantly higher when compared to the control group. Baseline laboratory values of both groups were shown in Table 2.

Although baseline MVA and echocardiographic parameters were similar in both groups, WS was significantly higher in the study group compared to the control group [8 (7-9) vs 9.5 (8-10), $\mathrm{p}=0.042]$. Baseline TTE and TEE measurements were shown in Table 3.

Procedural and post-procedural data for the patients were shown in Table 4. The control group patients without restenosis included data for their PMBV. The study group patients who had restenosis included data for their redo PMBV. The successful PMBV was achieved in $17(81.0 \%)$ patients of the study group and $138(87.9 \%)$ patients of the control group. Comparison of outcomes of procedures and post-procedural TTE measurements were shown in Table 4. Procedural

Table 2. Laboratory parameters of patients with and without restenosis

\begin{tabular}{|c|c|c|c|}
\hline & $\begin{array}{l}\text { Restenosis (-) } \\
(n=157)\end{array}$ & $\begin{array}{l}\text { Restenosis (+) } \\
(n=21)\end{array}$ & $\begin{array}{l}p \\
\text { value }\end{array}$ \\
\hline $\begin{array}{l}\text { Creatinine } \\
\text { (mg/dL) }\end{array}$ & $0.7(0.6-0.81)$ & $0.7(0.61-0.76)$ & 0.340 \\
\hline $\begin{array}{l}\text { Total } \\
\text { cholesterol } \\
\text { (mg/dL) }\end{array}$ & 177 (163-195) & 149(119-167) & 0.067 \\
\hline LDL (mg/dL) & $105(91-124)$ & $77(58-93)$ & 0.057 \\
\hline HDL (mg/dL) & $49 \pm 14$ & $54 \pm 17$ & 0.610 \\
\hline $\begin{array}{l}\text { Triglyceride } \\
\text { (mg/dL) }\end{array}$ & $114(71-145)$ & $84(44-101)$ & 0.201 \\
\hline $\begin{array}{l}\text { Leukocyte } \\
\left(10^{3} / \mathrm{mL}\right)\end{array}$ & $7.32(6.37-9.26)$ & $7.75(6.84-8.26)$ & 0.558 \\
\hline $\begin{array}{l}\text { Platelet } \\
\left(10^{3} / \mathrm{mL}\right)\end{array}$ & $210 \pm 49$ & $241 \pm 62$ & 0.010 \\
\hline $\begin{array}{l}\text { Plateletcrit } \\
(\%)\end{array}$ & $0.203(0.173-0.230)$ & $0.260(0.243-0.290)$ & $<0.001$ \\
\hline $\begin{array}{l}\text { Mean Platelet } \\
\text { Volume (fL) }\end{array}$ & $9.7(8.7-11.1)$ & $10.5(9.8-12.0)$ & 0.021 \\
\hline $\begin{array}{l}\text { Hemoglobin } \\
(\mathrm{g} / \mathrm{dL})\end{array}$ & $12.73 \pm 1.84$ & $12.44 \pm 1.54$ & 0.495 \\
\hline
\end{tabular}

LDL: Low-density lipoprotein, HDL: High-density lipoprotein, $n$ : Number Important $p$ values are written in bold. 
success rate and post-procedural TTE parameters except the mean gradient were similar between both groups. On the other hand, decrease in trans-mitral gradient was found to be significantly lower in the study group compared to the control group [5 (4-6) vs 6 (5-7), $\mathrm{p}=0.004]$.

ROC analysis was conducted to determine the optimal MPV and PCT cut-off values to indicate restenosis. The highest combined sensitivity and specificity values for MPV crossed the curve at 9.65 (sensitivity $81.0 \%$ and specificity $49.7 \%$ ) (Table 5). The area under the curve (AUC) was 0.656 (95\% CI: 0.541-0.770, $\mathrm{p}=0.021)$. The highest combined sensitivity and specificity values for PCT crossed the curve at 0.241 (sensitivity $76.2 \%$ and specificity $87.9 \%$ ). The AUC was 0.826 (95\% CI: 0.700 0.952, $\mathrm{p}<0.001$ ) (Figure 1).

A Kaplan-Meier survival analysis also revealed that long term restenosis rate was found to be significantly

Table 3. Pre-procedural transthoracic and transesophageal echocardiographic parameters of study groups prior to their first percutaneous mitral balloon valvuloplasty

\begin{tabular}{|c|c|c|c|}
\hline & $\begin{array}{l}\text { Restenosis }(-) \\
(n=157)\end{array}$ & $\begin{array}{l}\text { Restenosis (+) } \\
(n=21)\end{array}$ & $\begin{array}{l}p \\
\text { value }\end{array}$ \\
\hline Ejection fraction (\%) & $60(60-65)$ & $65(60-65)$ & 0.296 \\
\hline \multicolumn{4}{|l|}{ TTE } \\
\hline sPAP (mmHg) & $42(35-55)$ & $45(39-55)$ & 0.453 \\
\hline LA diameter (cm) & $4.5(4.2-4.8)$ & $4.7(4.4-4.9)$ & 0.111 \\
\hline Wilkins score & $8(7-9)$ & $9.5(8-10)$ & 0.042 \\
\hline $\begin{array}{l}\text { Planimetric MVA } \\
\left(\mathrm{cm}^{2}\right)\end{array}$ & $1.1(1.0-1.2)$ & $1.1(1.0-1.3)$ & 0.417 \\
\hline MVA PHT $\left(\mathrm{cm}^{2}\right)$ & $1.1(0.9-1.3)$ & $1.1(1.0-1.2)$ & 0.739 \\
\hline $\begin{array}{l}\text { Mean gradient } \\
(\mathrm{mmHg})\end{array}$ & $11(9-14)$ & $11(10-13)$ & 0.532 \\
\hline \multicolumn{4}{|l|}{ TEE } \\
\hline sPAP (mmHg) & $50(40-60)$ & $47(35-55)$ & 0.589 \\
\hline $\begin{array}{l}\text { Mean gradient } \\
(\mathrm{mmHg})\end{array}$ & $13(11-18)$ & $15.5(11-20)$ & 0.390 \\
\hline $\begin{array}{l}\text { Planimetric MVA } \\
\left(\mathrm{cm}^{2}\right)\end{array}$ & $1.0(0.9-1.2)$ & $1.0(0.85-1.2)$ & 0.528 \\
\hline MVA PHT $\left(\mathrm{cm}^{2}\right)$ & $1.1(0.98-1.2)$ & $1.0(0.9-1.3)$ & 0.715 \\
\hline Wilkins score & $8(7-8.5)$ & $8(7.5-9)$ & 0.144 \\
\hline
\end{tabular}

TTE: Transthoracic echocardiography, SPAP: Systolic pulmonary artery pressure, LA: Left atrium, MVA: Mitral valve area, PHT: Pressure halftime higher in patients with higher PCT (Log-Rang $\mathrm{p}<0.001)$ and MPV (Log-Rang p<0.001) values (Figure $2 \mathrm{~A}, \mathrm{~B}$ ).

\section{Discussion}

This study analyzed the predictors of mitral restenosis in patients who underwent PMBV. It demonstrated that PMBV was performed in eligible patients with procedural success rate of $87.0 \%$. According to our study, 21 out of 178 patients developed mitral restenosis following successful PMBV. Additional to that, patients who had restenosis after PMBV had significantly higher value in PLT indices such as PLT, PCT and MPV.

PMBV has been a choice for the treatment of patients with symptomatic significant mitral stenosis with favorable mitral valve morphology. Despite its favorable outcomes, studies have revealed high rates of restenosis with adverse clinical events in patients who underwent successful $\mathrm{PMBV}^{(18-21)}$. According to a study conducted by Farhat et al. ${ }^{(22)}$, incidence of restenosis after PMBV has been reported between $3 \%$ and $70 \%$ in one to three years. They also demonstrated that the risk of restenosis

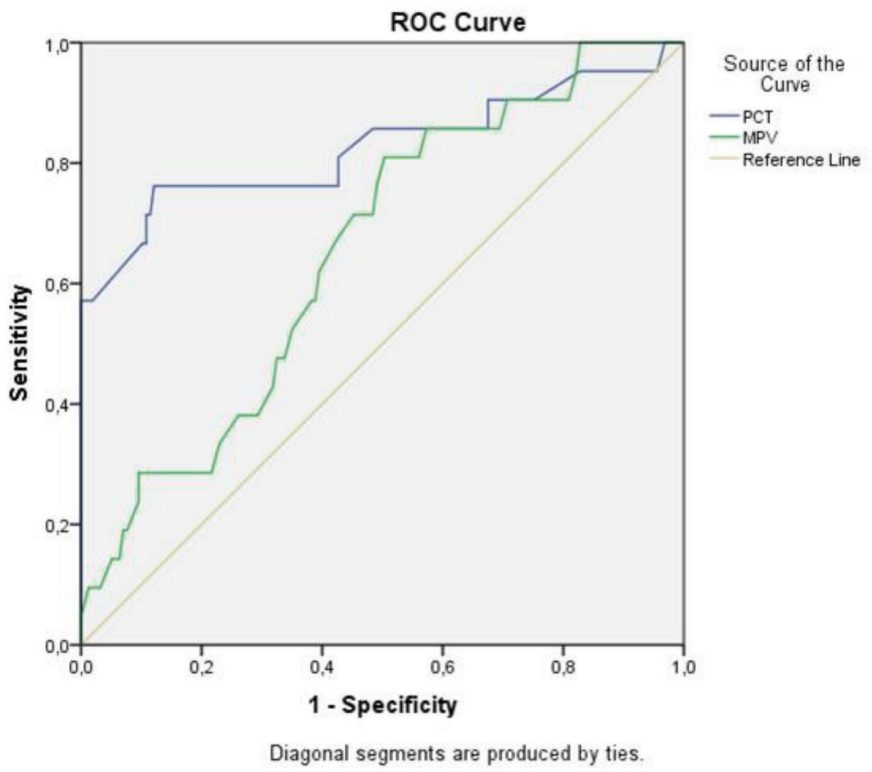

Figure 1. ROC analysis was conducted to determine the optimal MPV and PCT cut-off values to indicate restenosis

ROC: Receiver operating characteristic, MPV: Mean platelet volume, PCT: Platelecrit 
increased progressively during follow-up of these patients ( $77 \%$ at 10 years, $46 \%$ at 15 years and $18 \%$ at 18 years, respectively). In another study by Hernández et al. ${ }^{(2)}$, older patients (mean age 53 years) had higher rate of restenosis

A
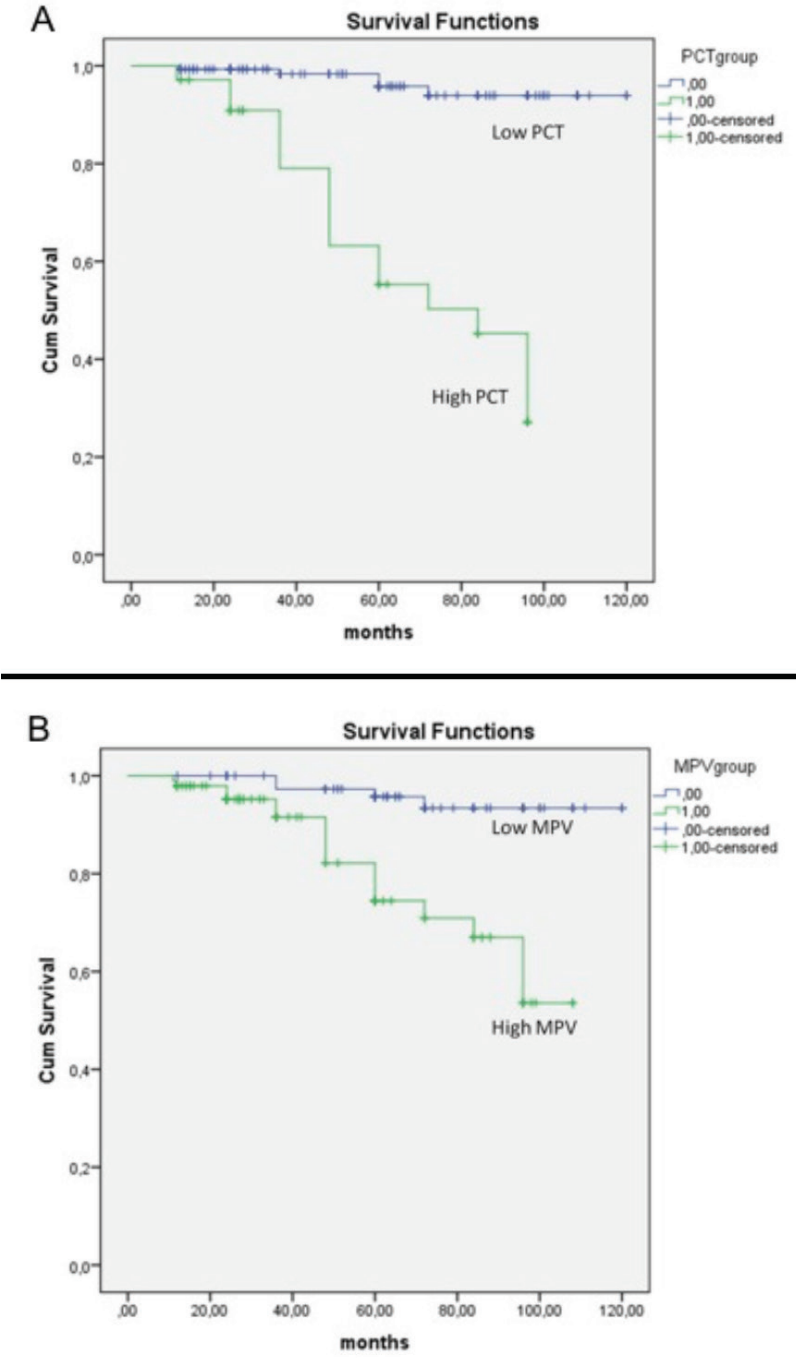

Figure 2. A Kaplan-Meier survival analysis also revealed that long term restenosis rate was found to be significantly higher in patients with higher PCT (A) and MPV (B) values PCT: Platelecrit, Cum: Cummulative, MPV: Mean platelet volume

Table 5. ROC analysis of platelet indices for mitral restenosis

\begin{tabular}{|l|l|l|l|l|l|}
\hline MPV & AUC & $95 \% \mathbf{C l}$ & Cut-off & Sensitivity & Specificity \\
\hline PCT & 0.656 & $0.541-0.770$ & $>9.65$ & 81.0 & 49.7 \\
\hline AUC & $95 \% \mathbf{C l}$ & Cut-off & Sensitivity & Specificity \\
\hline
\end{tabular}

ROC: Receiver operating characteristic, MPV: Mean platelet volume, PCT: Platelecrit, AUC: Area under curve, Cl: Confidence interval

(39\% restenosis rate at 7 years). Outcome of those studies demonstrated that major predictor factor for restenosis as WS, especially pre-procedural WS $\geq 8$ was associated with higher risk of restenosis. Previous studies also reported that post-procedurally estimated MVA and restenosis were

Table 4. Procedural and post-procedural data for the groups. Restenosis (+) group includes data of redo PMBV and restenosis (-) group includes data of PMBV

\begin{tabular}{|c|c|c|c|}
\hline & $\begin{array}{l}\text { Restenosis (-) } \\
(n=157)\end{array}$ & $\begin{array}{l}\text { Restenosis (+) } \\
(n=21)\end{array}$ & $\begin{array}{l}p \\
\text { value }\end{array}$ \\
\hline \multicolumn{4}{|l|}{ Post-procedural TTE } \\
\hline Ejection fraction (\%) & $60(60-65)$ & $60(60-65)$ & 0.967 \\
\hline sPAP $(\mathrm{mmHg})$ & $30(25-38)$ & $35(29-40)$ & 0.281 \\
\hline LA diameter $(\mathrm{cm})$ & $4.2(3.9-4.5)$ & $4.2(4.0-4.8)$ & 0.174 \\
\hline $\begin{array}{l}\text { Planimetric MVA } \\
\left(\mathrm{cm}^{2}\right)\end{array}$ & $1.8(1.6-2.0)$ & $1.8(1.6-1.9)$ & 0.568 \\
\hline MVA PHT $\left(\mathrm{cm}^{2}\right)$ & $1.8(1.6-2.0)$ & $1.8(1.65-2.05)$ & 0.938 \\
\hline $\begin{array}{l}\text { Mean gradient } \\
(\mathrm{mmHg})\end{array}$ & $5(4-6)$ & $6(5-7)$ & 0.004 \\
\hline $\begin{array}{l}\text { Balloon diameter } \\
(\mathrm{mm})\end{array}$ & $28(28-28)$ & $28(26-28)$ & 0.254 \\
\hline \multicolumn{4}{|l|}{ Balloon inflation } \\
\hline 1 time & $24(18.2)$ & $2(11.8)$ & \multirow{4}{*}{0.569} \\
\hline 2 times & $84(63.6)$ & $10(58.8)$ & \\
\hline 3 times & $22(16.7)$ & $5(29.4)$ & \\
\hline 4 times & $2(1.5)$ & $0(0)$ & \\
\hline $\begin{array}{l}\text { Procedural need for } \\
\text { emergent surgery }\end{array}$ & $9(5.7)$ & $0(0)$ & - \\
\hline Severe MR (n, \%) & $5(3.2)$ & $0(0)$ & - \\
\hline Tamponade (n, \%) & $4(2.5)$ & $0(0)$ & - \\
\hline \multicolumn{4}{|l|}{ Emergent intervention } \\
\hline $\operatorname{MVR}(n, \%)$ & $8(5.1)$ & $0(0)$ & - \\
\hline Comissurotomy (n, \%) & $1(0.6)$ & $0(0)$ & - \\
\hline $\begin{array}{l}\text { Procedural success } \\
(\mathrm{n}, \%)\end{array}$ & $138(87.9)$ & $17(81.0)$ & 0.277 \\
\hline
\end{tabular}


closely related to long-term clinical results of $\mathrm{PMBV}^{(23,24)}$. On this basis, they have hypothesized that complete commissurotomy resulting in larger MVA might prevent fibrous fusion of split commissures and restenosis ${ }^{(25)}$. Similar findings were also documented by Ruiz et al. ${ }^{(26)}$, they demonstrated that old age, heavy calcification, high WS, and suboptimal opening of mitral valve were major predictive factors for restenosis.

In our study, major predictors of restenosis were high levels of WS, previous history of mitral valve intervention and higher levels of post-procedurally estimated transmitral gradient, which were compatible with previous studies. Additionally, we also demonstrated a strong association between higher values of pre-procedural PLT indices, including PLT count, MPV and PCT and rate of restenosis. To the best our knowledge, this is the first study in literature which revealed a relationship between PLT indices and mitral restenosis.

Evidence from several studies has shown that MPV is a reliable method for measuring PLT size which indicates PLT function. Compared to normal size counterparts, larger PLT has higher hemostatic activity and contributes to the development of increased pro-coagulant activity of PLT, thrombosis and tromboembolism. According to those studies, severe rheumatic mitral stenosis is associated with increased risk for pro-coagulant activity of PLT and thrombosis. The presence of endothelial dysfunction and turbulent blood flow as a result of mitral valve stenosis were possible underlying mechanisms ${ }^{(27-29)}$. Similar results were demonstrated by Erdogan et al. ${ }^{(30)}$ in patients with rheumatic mitral stenosis. According to their study, patients with rheumatic mitral stenosis had a higher MPV than healthy controls $[9.05 \pm 1.26$ vs $7.56 \pm 0.74 \mathrm{fl}, \mathrm{p}<0.001]$ and those patients had higher PLT activity than controls ${ }^{(30)}$. In another study, Chen et al. ${ }^{(11)}$ reported increased peripheral venous PLT P-selectin expression in patients with moderate to severe rheumatic mitral stenosis compared to healthy counterparts. They also demonstrated a relationship between the amount of regional left atrial PLT P-selectin expression and the severity of mitral stenosis.
Calculated PCT in a blood sample is known to be an indicator of PLT mass in the blood just as hematocrit which is an indicator of total erythrocyte mass in the blood. Compared to total PLT count, PCT is turned out to be the best parameter in terms of estimating the PLT activity ${ }^{(31)}$. These findings in these studies demonstrate the close relationship between PLT activity and severity of rheumatic involvement of mitral stenosis.

Apart from above mentioned parameters, our study has also revealed that patients who underwent redo PMBV has a higher incidence of AF, which has been reported as a strong predictor of late outcome in series of balloon and surgical commissurotomy procedures ${ }^{(32,33)}$. The literature showed the association between increased PLT activation and AF. However, the studies proved that this activation was mostly related to MVA and severity of mitral valve disease ${ }^{(34)}$. Therefore, it was suggested that PLT activity, spontaneous echo contrast, mitral valve disease and AF were closely related to each other and AF seemed to be not the cause of increased PLT activity but the severity of mitral valve disease corresponded with the activation $^{(35)}$.

\section{Study Limitations}

There were several limitations in our study. First, and foremost, the retrospective nature of the study inherently limits the generalizability of our results. Another limitation of our study was relatively a small sample size with a short follow-up time. Although clinical characteristics and immediate post-procedural outcomes of our study were similar to the previous studies, our study population consisted of relatively young patients compared to those studies. Outcomes of this study may not be extrapolated to older patients with less favorable valve characteristics. In addition, we did not assess novel markers of PLT activation status such as soluble P-selectin or soluble CD40 ligand. Further prospective studies with novel PLT activation markers should be implemented to clarify the relationship between PLT indices and the incidence of mitral restenosis following PMBV. 


\section{Conclusion}

Estimated WS and post-procedural MVA (MVA $\leq 1.5$ $\mathrm{cm}^{2}$ ) seem to be still superior than other parameters to predict restenosis after PMBV. However, PLT indices including PLT count, MPV and PCT might be feasible and easy parameters to predict possible restenosis after PMBV.

\section{Ethics}

Ethics Committee Approval: This study was approved by the Mehmet Akif Ersoy Thoracic and Cardiovascular Surgery Training and Research Hospital Ethics Committee (decision no: 2020/58, date: 18.08.2020).

Informed Consent: Informed consent was obtained from all patients in accordance with a protocol.

Peer-review: Externally peer-reviewed.

\section{Authorship Contributions}

Concept: Ö.T., A.A.Ş., Ö.Ç., Design: Ö.T., A.A.Ş., Ö.Ç., Data Collection or Processing: Ö.T., M.D., Analysis or Interpretation: A.A.Ş., M.D., S.K., Literature Search: Ö.T., M.D., Writing: Ö.T., A.A.Ş., M.D., S.K., Ö.Ç.

Conflict of Interest: All authors declare no conflict of interest.

Financial Disclosure: No funding was received.

\section{References}

1. Iung B, Garbarz E, Michaud P, et al. Immediate and mid-term results of repeat percutaneous mitral commissurotomy for restenosis following earlier percutaneous mitral commissurotomy. Eur Heart J 2000;21:1683-9.

2. Hernández R, Bañuelos C, Alfonso F, et al. Long-term clinical and echocardiographic follow-up after percutaneous mitral valvuloplasty with the Inoue balloon. Circulation 1999;99:1580-6.

3. Iung B, Garbarz E, Michaud P, et al. Late results of percutaneous mitral commissurotomy in a series of 1024 patients. Analysis of late clinical deterioration: frequency, anatomic findings, and predictive factors. Circulation 1999;99:3272-8.

4. Farhat M, Ayari M, Maatouk F, et al. Percutaneous balloon versus surgical closed and open mitral commissurotomy. Seven year follow-up results of a randomised trial. Circulation 1998;97:245-50.

5. Abascal VM, Wilkins GT, Choong CY, et al. Echocardiographic evaluation of mitral valve structure and function in patients followed for at least six months after percutaneous balloon mitral valvuloplasty. J Am Coll Cardiol 1988;12:606-15

6. Wilkins GT, Weyman AE, Abascal VM, Block PC, Palacios IF. Percutaneous balloon dilation of the mitral valve: an analysis of echocardiographic variables related to outcome and the mechanism of dilation. Br Heart J 1988;60:299-308.

7. Cannan CR, Nishimura RA, Reeder GS, et al. Echocardiographic assessment of commissural calcium: a simple predictor of outcome after percutaneous mitral balloon valvotomy. J Am Coll Cardiol 1997;29:175-80.

8. Fawzy ME, Shoukri M, Hassan WH, et al. The impact of mitral valve morphology on the long-term outcome of mitral balloon valvuloplasty. Catheter Cardiovasc Interv 2007;69:40-6.

9. Fawzy ME, Shoukri M, Fadel B, et al. Long-term (up to 18 years) clinical and echocardiographic results of mitral balloon valvuloplasty in 531 consecutive patients and predictors of outcome. Cardiology 2009;113:213-21.

10. Chen MC, Wu CJ, Chang HW, et al. Left atrial platelet activity with rheumatic mitral stenosis: correlation study of severity and platelet P-selectin expression by flow cytometry. Chest 2003;124:1663-9.

11. Chen MC, Chang HW, Juang SS, Yip HK, Wu CJ. Increased plasma levels of soluble P-selectin in rheumatic mitral stenosis. Chest 2004;126:54-8.

12. Hasan-Ali H, Mosad E. Changes in platelet, coagulation, and fibrinolytic activities in mitral stenosis after percutaneous mitral valvotomy: role of hemodynamic changes and systemic inflammation. Clin Appl Thromb Hemost 2015;21:339-47.

13. Chandrashekar V. Plateletcrit as a screening tool for detection of platelet quantitative disorders. J Hematol 2013;2:22-6.

14. Giacomini A, Legovini P, Gessoni G, et al. Platelet count and parameters determined by the Bayer ADVIA 120 in reference subjects and patients. Clin Lab Haematol 2001;23:181-6.

15. Quinones MA, Otto CM, Stoddard M, Waggoner A, Zoghbi WA Recommendations for quantification of Doppler echocardiography: a report from the Doppler Quantification Task Force of the Nomenclature and Standards Committee of the American Society of Echocardiography. J Am Soc Echocardiogr 2002;15:167-84.

16. Inoue $\mathrm{K}$, Owaki $\mathrm{T}$, Nakamura $\mathrm{T}$, Kitamura F, Miyamoto $\mathrm{N}$. Clinical application of transvenous mitral commissurotomy by a new balloon catheter. J Thorac Cardiovasc Surg 1984;87:394-402.

17. Palacios IF. Percutaneous mitral balloon valvuloplasty. In: Sievert H (eds). Percutaneous Interventions for Congenital Heart Disease. London: Informa Healthcare; 2007 p.177e184.

18. Kang DH, Park SW, Song JK, et al. Long term clinical and echocardiographic outcome of percutaneous mitral valvuloplasty: randomized comparison of inoue and double balloon techniques. J Am Coll Cardiol 2000;35:169-75.

19. Wang A, Krasuski RA, Warner JJ, et al. Serial echocardiographic evaluation of restenosis after successful percutaneous mitral commissurotomy. J Am Coll Cardiol 2002;39:328-34.

20. Pavlides GS, Nahhas GT, London J, et al. Predictors of long term event free survival after percutaneous balloon mitral valvuloplasty. Am J Cardiol 1997;79:1370-4.

21. Palacios IF, Sanchez PL, Harrel LC, Weyman AE, Block PC. Which patients benefits from percutaneous balloon mitral valvuloplasty? Prevalvuloplasty 
and postvalvuloplasty variables that predict long term outcome. Circulation 2002;105:1465-71.

22. Farhat BM, Betbout F, Gamra H, et al. Predictors of long-term event free survival of freedom from restenosis after percutaneous balloon mitral commissurotomy. Am. Heart J 2001;142:1072-9.

23. Arora R, Kalra GS, Murty GS, et al. Percutaneous transatrial mitral commissurotomy: immediate and intermediate results. J Am Coll Cardiol 1994;23:1327-32.

24. Tuzcu EM, Block PC, Griffin BP, et al. Percutaneous mitral balloon valvotomy in patients with calcific mitral stenosis: immediate and longterm outcome J Am Coll Cardiol 1994;23:1604-9.

25. Waller BF, Van Tassel JW, Mckay C. Anatomic basis for and morphologic changes produced by catheter balloon valvuloplasty. In: Bashore TM, Davidson CJ (eds). Bailtimore; Percutaneous Balloon Valvuloplasty and Related Techniques, Williams \& Wilkins: 1991 p. 33-6. Doi: 10.1002/ clc. 4960130913 .

26. Ruiz CE, Zhang HP, Gamra H, Allen JW, Lau FYK. Late clinical and echocardiographic follow up after percutaneous balloon dilatation of the mitral valve. Br Heart J 1994;71:454-8.

27. Varol E, Ozaydin M, Turker Y, Alaca S. Mean platelet volume, an indicator of platelet activation, is increased in patients with mitral stenosis and sinus rhythm. Scand J Clin Lab Invest 2009;69:708-12.

28. Thompson CB, Jakubowski JA, Quinn PG, Deykin D, Valeri CR. Platelet size and age determine platelet function independently. Blood 1984;63:1372-5.
29. Yavuz B, Ertugrul DT, Yalcin AA, Kucukazman M, Ata N, Dal K. Increased mean platelet volume in rheumatic mitral stenosis: A possible factor for thromboembolic events. J Cardiol 2009;53:204-7.

30. Erdogan D, Icli A, Aksoy F, et al. Percutaneous mitral balloon valvuloplasty reduces mean platelet volume in patients with rheumatic mitral stenosis. Scand J Clin Lab Invest 2012;72:452-8.

31. Tvedten H, Lilliehöök I, Hillström A, Häggström J. Plateletcrit is superior to platelet count for assessing platelet status in Cavalier King Charles Spaniels. Vet Clin Pathol 2008;37:266-71.

32. Palacios IF, Tuzcu ME, Weyman AE, Newell JB, Block PC. Clinical follow-up of patients undergoing percutaneous mitral balloon valvotomy. Circulation 1995;91:671-6.

33. Hickey MSJ, Blackstone EH, Kirklin JW, Dean LS. Outcome probabilities and life history after surgical mitral commissurotomy: implications for balloon commissurotomy. J Am Coll Cardiol 1991;17:29-42.

34. Kataoka H, Yano S, Mikuriya Y. [Relationship of mitral valve area to hemostatic condition in rheumatic mitral stenosis]. J Cardiol 1994;24:38795 .

35. Kamath S, Blann AD, Lip GY. Platelets and atrial fibrillation. Eur Heart J 2001;22:2233-42. 